\title{
Semi-Biosynthesis of Magnetite-Gold Composite Nanoparticles Using an Ethanol Extract of Eucalyptus camaldulensis and Study of the Surface Chemistry
}

\author{
Emad al din Haratifar, ${ }^{1}$ Hamid Reza Shahverdi, ${ }^{1}$ Mojtaba Shakibaie, ${ }^{2,3}$ \\ Kamyar Mollazadeh Moghaddam, ${ }^{4}$ Mohsen Amini, ${ }^{5}$ Hojatollah Montazeri, ${ }^{3}$ \\ and Ahmad Reza Shahverdi ${ }^{3}$ \\ ${ }^{1}$ Department of Materials Engineering, University of Tarbiat Modares, 14115-143 Tehran, Iran \\ ${ }^{2}$ Department of Pharmaceutical Biotechnology, Faculty of Pharmacy, Kerman University of Medical Sciences, \\ 76175-493 Kerman, Iran \\ ${ }^{3}$ Department of Pharmaceutical Biotechnology and Medicinal Plants Research Center, Faculty of Pharmacy, \\ Tehran University of Medical Sciences, 1417614411 Tehran, Iran \\ ${ }^{4}$ Biotechnology Research Center, Faculty of Pharmacy, Tehran University of Medical Sciences, 1417614411 Tehran, Iran \\ ${ }^{5}$ Department of Medicinal Chemistry, Faculty of Pharmacy, Tehran University of Medical Sciences, 1417614411 Tehran, Iran
}

Correspondence should be addressed to Ahmad Reza Shahverdi, shahverd@sina.tums.ac.ir

Received 18 August 2009; Accepted 9 December 2009

Recommended by Jun Liu

Green synthesis of metal nanoparticles, such as silver or gold nanoparticles, has been attracting increasing attention in recent years. Functionalized magnetite nanoparticles have many uses in various applications, including nanoelectronic devices, molecular recognition, biomedical applications, drug delivery targeting, and optical devices. In this investigation, magnetic cores $\left(\mathrm{Fe}_{3} \mathrm{O}_{4}\right)$ were synthesized using a fabrication method involving coprecipitation of $\mathrm{Fe}^{2+}$ and $\mathrm{Fe}^{3+}$. In the next step, magnetite-gold composite nanoparticles were synthesized with size ranging from 6-20 nm, using an ethanol extract of Eucalyptus camaldulensis as a natural reducing agent. Transmission electron microscopy, energy-dispersive spectroscopy, X-ray diffraction spectroscopy, and visible absorption spectroscopy confirmed the fabrication of magnetite-gold composite nanoparticles. In the UV spectra diagram, a redshift of the surface plasmon of the Au was evidence that contact between gold and $\mathrm{Fe}_{3} \mathrm{O}_{4}$ had occurred. The surface chemistry of the as-prepared magnetite-gold nanoparticles was studied using infrared spectroscopy. The presence of organic compounds with a carboxyl moiety was confirmed on the surface of the magnetite-gold nanoparticles fabricated by this combined chemical and biological reducing process, which we have designated as a semi-biosynthesis method.

Copyright (C) 2009 Emad al din Haratifar et al. This is an open access article distributed under the Creative Commons Attribution License, which permits unrestricted use, distribution, and reproduction in any medium, provided the original work is properly cited.

\section{Introduction}

Composite nanoparticles that contain two or more different nanoscale materials are of increasing interest in present day research because of their unique properties. These nanoparticles, have many applications in a number of fields, including use in nanoelectronic devices, molecular recognition, biomedical applications, and optical devices [1]. Recently, different nanocomposite materials, such as $\mathrm{SiO}_{2}$ coated $\mathrm{Fe}$ nanocapsules, cobalt ferrite core/shell nanoparticles, silver/polystyrene nanospheres, $\mathrm{Au}-\mathrm{Cu}_{2} \mathrm{O}$ core-shell nanocubes, and $\mathrm{Al}_{2} \mathrm{O}_{3}$-Co nanocapsules have been synthesized by different fabrication methods [2-5]. One of the prevalent nanostructures that has many uses in biomedicine is the magnetic nanoparticle. Magnetic nanoparticles, for instance those composed of magnetite $\left(\mathrm{Fe}_{3} \mathrm{O}_{4}\right)$ or maghemite $\left(\gamma-\mathrm{Fe}_{2} \mathrm{O}_{3}\right)$, have unique thermal, chemical, and magnetic properties that make them particularly well suited for medical applications [6].

However, materials that are used in medical diagnoses or as therapeutic agents require specific characteristics, such as colloidal stability [7], biocompatibility [8], resistance against 
environmental degradation [2], and nontoxicity [6]. For these applications, nanoparticles must be passivated with an external inert shell in order to protect the magnetic core against oxidation. Moreover, the surfaces of these particles should be functionalized with organic molecules in order to allow them to chemically bind with biomolecules like DNA, proteins, amino acids, and so forth [9].

At present, a number of different methods have been reported for coating magnetic nanoparticles. Protective layers include polymeric molecules such as polyethylene glycol and dextran or inorganic compounds like silica [8]. Although some of these methods have been recently commercialized, most have substantial deficiencies. For example, hydrophobic surfaces arising from polymeric chains can result in improper protein bonding [10]. A nonmetallic coating also potentially decreases the magnetic properties of iron-oxide nanoparticles, thus limiting the applications of these particles [11].

Among the different techniques available for surface modifications, gold-coated magnetic nanoparticles have lately attracted significant attention. Since gold is an inert element from the viewpoint of chemical reactivity, it is very useful as a coating for protecting magnetic nanoparticles. Kinoshita et al. synthesized a gold-iron nanocomposite powder by a reverse micelle method [12]. Similar structures of $\mathrm{Fe} / \mathrm{Au}$ nanoparticles have been successfully synthesized and the particles used as a magnetic resonance (MR) contrast agent [13]. According to $\mathrm{Yu}$ et al. and $\mathrm{Au}-\mathrm{Fe}_{3} \mathrm{O}_{4}$ nanoparticles with dumbbell-like shapes could be prepared via decomposition of iron pentacarbonyl, $\mathrm{FeCO}_{5}$, onto the surface of gold nanoparticles [14]. In other work, gold and magnetite composite nanoparticles have been prepared by a laser process in water [15]. Gold-coated ferric oxide nanoparticles have been obtained using sodium citrate as the reducing agent, yielding particles with an average size of $25 \mathrm{~nm}$, as reported by Pham et al [6]. Amino acids have also been adsorbed onto the $\mathrm{Au} / \gamma-\mathrm{Fe}_{2} \mathrm{O}_{3}$ composite nanoparticles synthesized by gamma-ray irradiation [9].

A number of these methods for synthesizing gold-iron oxide nanocomposites may not be suitable for biological application because they use harmful surfactants or organic solvents. In addition, maintaining the magnetic nanoparticles in liquid media and preventing aggregation are difficult in practice. In the current study, $\mathrm{Au}-\mathrm{Fe}_{3} \mathrm{O}_{4}$ composite nanoparticles were prepared with a combined chemical and biological reducing process, designated here as a semibiosynthesis method. Magnetic cores $\left(\mathrm{Fe}_{3} \mathrm{O}_{4}\right)$ were primarily synthesized using a fabrication method consisting of coprecipitation of $\mathrm{Fe}^{2+}$ and $\mathrm{Fe}^{3+}$. An ethanol extract of Eucalyptus camaldulensis [16] was used for the reduction of $\mathrm{Au}^{+3}$ on the surface of the $\mathrm{Fe}_{3} \mathrm{O}_{4}$ magnetic nanoparticles and for the functionalization of the $\mathrm{Au}-\mathrm{Fe}_{3} \mathrm{O}_{4}$ nanocomposite particles.

\section{Experimental}

Magnetite $\left(\mathrm{Fe}_{3} \mathrm{O}_{4}\right)$ nanoparticles were prepared at room temperature by a previously reported method [17]. Briefly, deionized water $(200 \mathrm{ml})$ was deoxygenated by bubbling nitrogen gas for 1.5 hour, then $50 \mathrm{ml}$ of $\mathrm{NH}_{4} \mathrm{OH}(1 \mathrm{M})$ was added, and the mixture was stirred with mechanical agitation at $1000 \mathrm{rpm}$. Next, $6.76 \mathrm{~g} \mathrm{FeCl}_{3} .6 \mathrm{H}_{2} \mathrm{O}(2.5 \mathrm{mmol})$ and $4.97 \mathrm{~g}$ $\mathrm{FeCl}_{2} .4 \mathrm{H}_{2} \mathrm{O}(2.5 \mathrm{mmol})$ were separately dissolved in $50 \mathrm{ml}$ distilled water to make $0.5 \mathrm{M}$ solutions. Subsequently, $10 \mathrm{ml}$ of the ferrous chloride and $20 \mathrm{ml}$ of the ferric chloride solutions were added to the mentioned ammonium hydroxide solution and the reaction mixture was stirred for 2.5 minutes at $1000 \mathrm{rpm}$. At this stage, a black precipitate formed and it was washed four times with deionized water. The prepared magnetite $\left(\mathrm{Fe}_{3} \mathrm{O}_{4}\right)$ nanoparticles were separated from the solution with a magnet.

The reduction of the $\mathrm{Au}^{3+}$ onto the surface of magnetite $\left(\mathrm{Fe}_{3} \mathrm{O}_{4}\right)$ nanoparticles was carried out using an ethanol extract prepared from E.camaldulensis whole plant [16]. Chloroauric acid was purchased from Merck, Germany. Magnetic nanoparticles (200 mg) were dispersed in $100 \mathrm{~mL}$ of aqueous $\mathrm{HAuCl}_{4}$ (chloroauric acid) solution $(1 \mathrm{mM})$ and mixed with $10 \mathrm{~mL}$ of an ethanol extract of E.camaldulensis $(10 \mathrm{mg} / \mathrm{mL})$. The resulting mixture was allowed to stand for 15 minutes at room temperature, then the prepared magnetite-gold nanocomposites were separated from the colloid by a magnet. Finally, the nanoparticles were washed three times with distilled water for use in further experiments.

The UV-visible spectra of the magnetite nanoparticles and magnetite-gold nanocomposites samples, before and after separation with the magnet, were measured on a Labomed Model UVD-2950 UV-VIS Double Beam PC Scanning spectrophotometer, operated at a resolution of $2 \mathrm{~nm}$. All samples were characterized by transmission electron microscopy (model EM 208 Philips), energy-dispersive spectroscopy (EDS), and X-ray diffraction spectroscopy. The surface chemistry of the separated magnetite-gold nanocomposites was further studied with Fourier transform infrared spectroscopy (Nicolet Magna 550).

\section{Results and Discussion}

This study reports a new method for preparation of functionalized magnetite-gold nanocomposites that used a combined chemical and biological procedure. In the first stage, $\mathrm{Fe}_{3} \mathrm{O}_{4}$ magnetite nanoparticles were chemically synthesized and their shape and size were studied by transmission electron microscopy. Figures 1(a) and 1(b) show different representative TEM images recorded from the drop-coated film of the magnetite nanoparticles synthesized by this method [17]. The particle size histogram of the synthesized $\mathrm{Fe}_{3} \mathrm{O}_{4}$ nanoparticles shows that the particles ranged in size from 6 to $20 \mathrm{~nm}$, with an average size of $10 \mathrm{~nm}$ (Figure $1(\mathrm{c})$ ). As can be seen in Figures 1(a) and 1(b), the broad surface area of the nanoparticles and the magnetic forces between them could cause a considerable agglomeration between the fabricated $\mathrm{Fe}_{3} \mathrm{O}_{4}$ magnetite nanoparticles [18]. The histogram of magnetite nanoparticle size dispersion obtained from TEM images showed diameter ranges between 6-20 nm with an average of $10 \mathrm{~nm}$ (Figure 1(c)).

Analysis of the $\mathrm{Fe}_{3} \mathrm{O}_{4}$ nanoparticles by energy dispersive spectroscopy (EDS) confirmed the presence of Fe and $\mathrm{O}$ element signals (Figure 1(d)). The peaks shown in Figure 1(d) were attributed to Fe and $\mathrm{O}$ elements, which confirmed the 


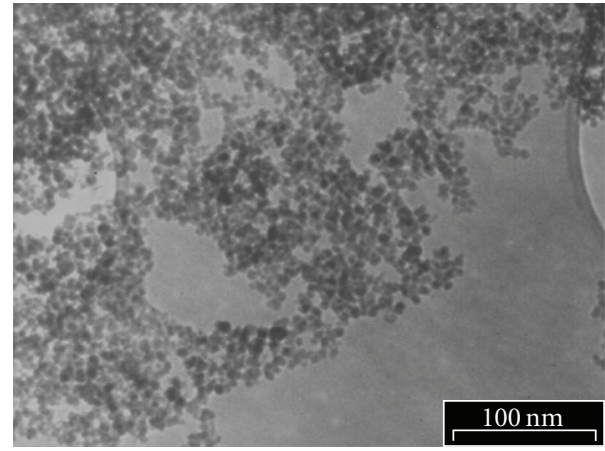

(a)

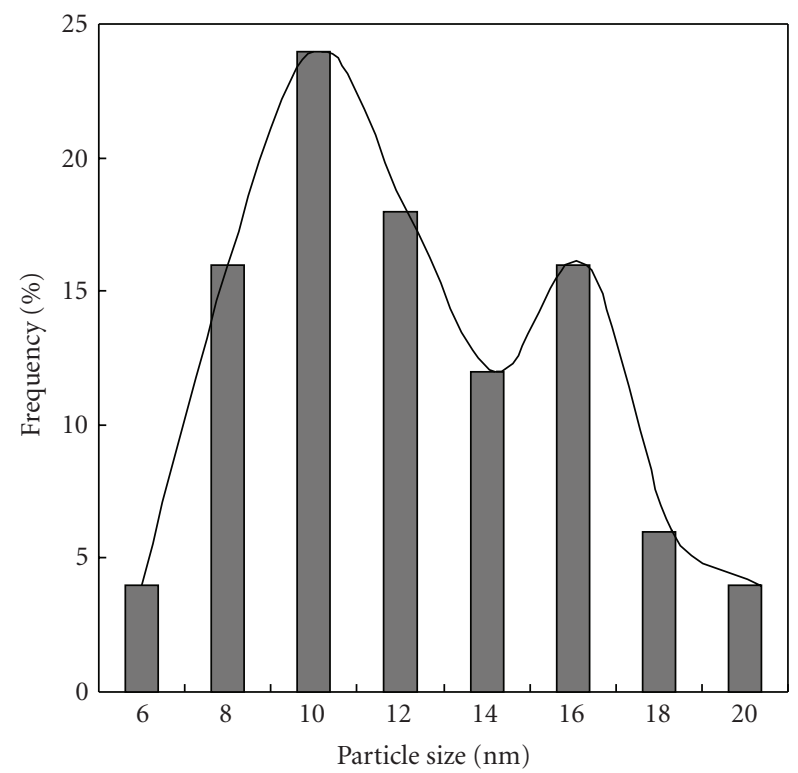

(c)

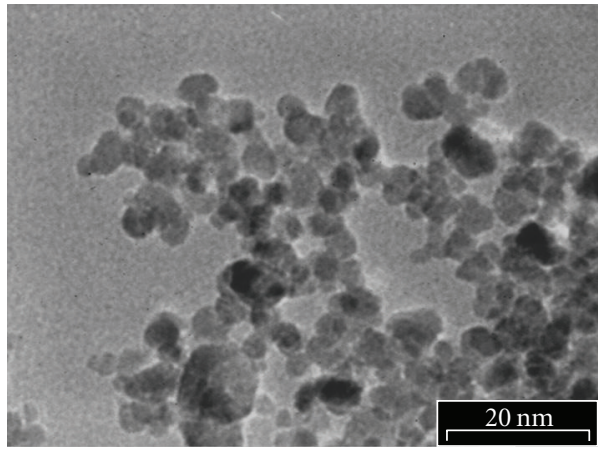

(b)

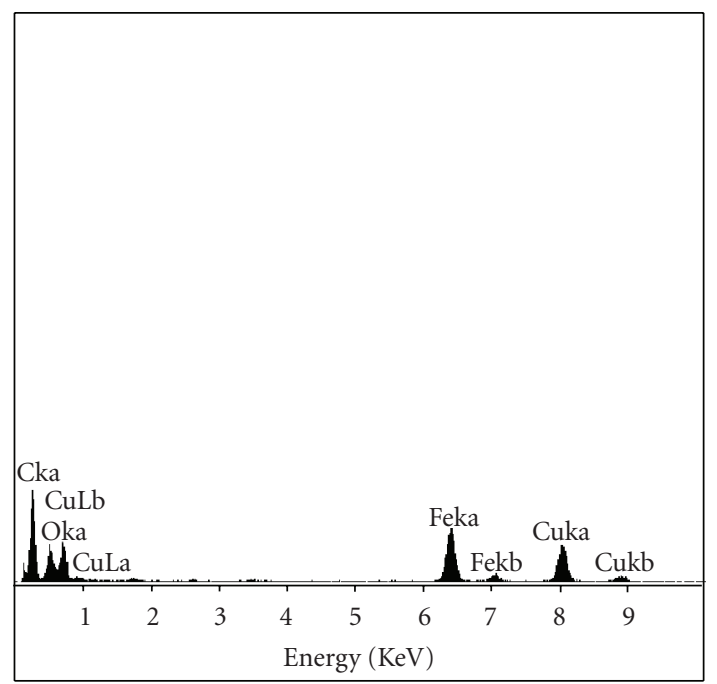

(d)

Figure 1: TEM images of magnetic nanoparticles with low (a) and high (b) magnifications, (c) Particle size distribution histogram of $\mathrm{Fe}_{3} \mathrm{O}_{4}$ nanoparticles, (d) EDS spectrum of magnetite particles.

existence of iron-oxide nanoparticles (copper and carbon peaks existed due to the grid used for TEM imaging). In the second stage, the magnetite-gold nanocomposite was fabricated in the presence of $\mathrm{Au}^{3+}$ by adding an ethanol extract of E. camaldulensis as a reducing agent. The TEM images of the magnetite-gold nanocomposite illustrated in Figure 2 show gold nanoparticles as dark spots. In contrast, $\mathrm{Fe}_{3} \mathrm{O}_{4}$ magnetite nanoparticles are observed as a gray color because elemental gold $(\mathrm{Au})$ has a higher electron density than $\mathrm{Fe}_{3} \mathrm{O}_{4}$ and subsequently more electrons are transmitted in bright field imaging [14].

The EDS pattern of the separated $\mathrm{Fe}_{3} \mathrm{O}_{4}$ magnetitegold nanocomposite indicated the presence of gold, iron, and oxygen, as illustrated in Figure 3. The EDS experiment was repeated for different nanoparticles and the obtained EDS spectra confirmed that the formed nanoparticles were comprised of both elemental gold and $\mathrm{Fe}_{3} \mathrm{O}_{4}$ magnetite ingredients. The UV-Visible spectra were examined before and after separation of the magnetic nanoparticles from the gold nanoparticles (Figure 4). Plasmon resonance peaks detected after removing the magnetic nanoparticles from the reaction mixture established the formation of magnetitegold nanocomposites. It should be noted that pure ironoxide did not show a significant plasmon resonance peak in the absence of gold nanoparticles. As seen in Figure 4, the highest absorbance was observed for gold nanoparticles located at $530 \mathrm{~nm}$ (solid line curve), whereas Au$\mathrm{Fe}_{3} \mathrm{O}_{4}$ composite nanoparticles showed a maximum peak at $608 \mathrm{~nm}$ (dotted line) which agreed with other previous reports $[2,9,14,19]$. This wavelength shift in the gold surface plasmon, known as red-shift, is a probable occurrence and has been reported previously $[9,12,14,19]$.

The XRD method was further used to determine the chemical composition of the nanocomposites (Figure 5). The $\mathrm{Fe}_{3} \mathrm{O}_{4}$ and $\mathrm{Au}$ peaks were observed and again verified the connection of magnetite nanoparticles with elemental gold. The pattern of gold nanoparticles was face-centered cubic, and the dominant crystal plane for these particles 


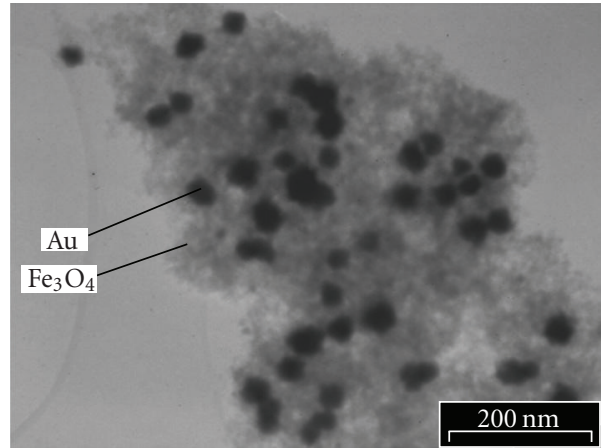

(a)

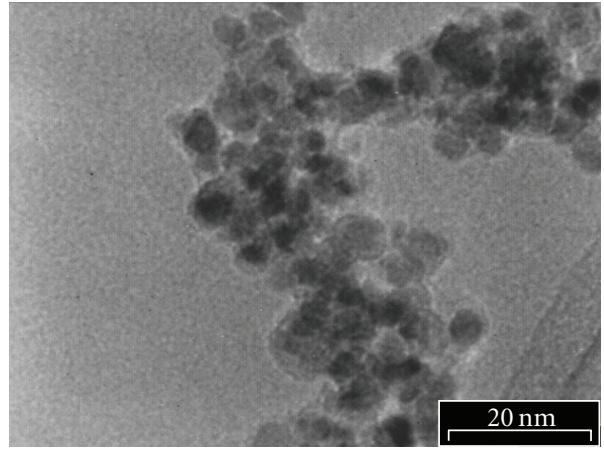

(b)

FIgURE 2: TEM images of magnetic-gold composite nanoparticles with low (a) and high (b) magnifications. Dark particles represent gold, and gray particles are magnetite.

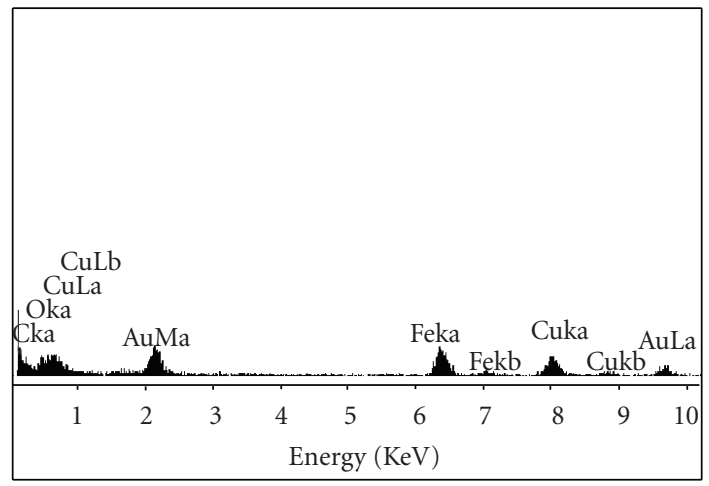

FIGURE 3: EDS pattern of magnetite-gold composite nanoparticles.

was (111). The surface chemistry of the prepared magnetitegold nanocomposites was studied using infrared (IR) spectroscopy and the IR peaks centered at $3426 \mathrm{~cm}^{-1}$ and $1675 \mathrm{~cm}^{-1}$ confirmed the presence of a carboxyl group on the surface of the semi-biosynthesized magnetite-gold nanocomposites (spectrum not shown).

\section{Conclusion}

In this study, the green synthesis and functionalization of a $\mathrm{Au}-\mathrm{Fe}_{3} \mathrm{O}_{4}$ nanocomposite (from $\mathrm{Fe}_{3} \mathrm{O}_{4}$ magnetic nanoparticles) were performed using an ethanol extract of E. camaldulensis. As one advantage, a carboxyl group was detected on the surface of the prepared $\mathrm{Au}-\mathrm{Fe}_{3} \mathrm{O}_{4}$ nanocomposite, which would make these particles suitable for rapid separation and purification of biomolecules by magnetic field and drug delivery. It should be noted that the importance of the external inert shell in protecting the magnetic core against oxidation is well established but however, in this study we prepared the $\mathrm{Au}-\mathrm{Fe}_{3} \mathrm{O}_{4}$ nanocomposites that may have contained some portions of $\mathrm{Au}-\mathrm{Fe}_{3} \mathrm{O}_{4}$ core-shell nanoparticles. Further treatments such as acid washing can be used for separation of the $\mathrm{Au}-\mathrm{Fe}_{3} \mathrm{O}_{4}$ core-shell fraction and merit further investigation. Moreover, since surfactant has not been used for functionalization of these nanocomposites, this makes these nanoparticles also potentially useful for biomedical applications.

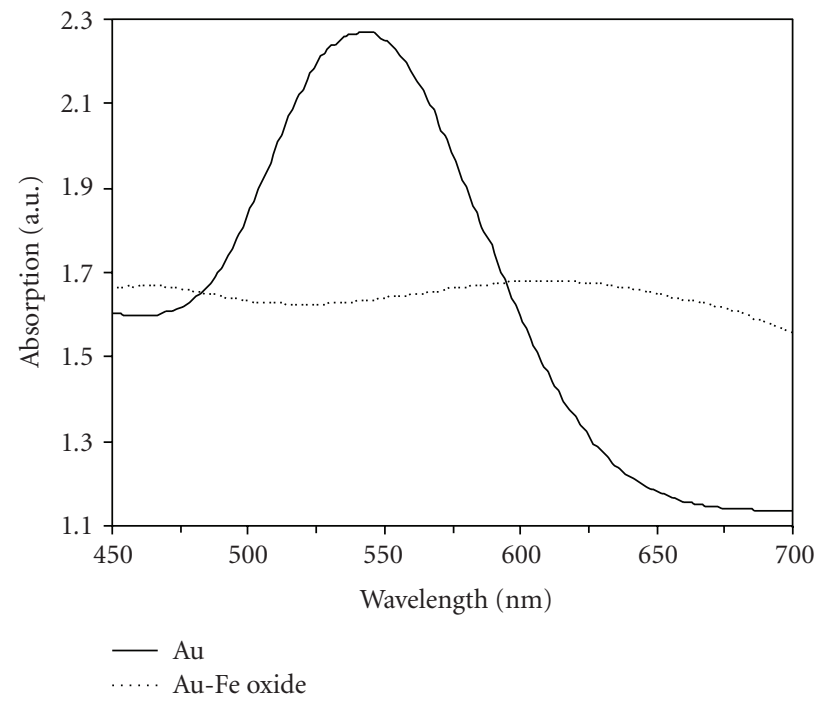

FIGURE 4: Absorbance spectra of gold nanoparticles (solid line) and magnetite-gold composite nanoparticles (dotted line).

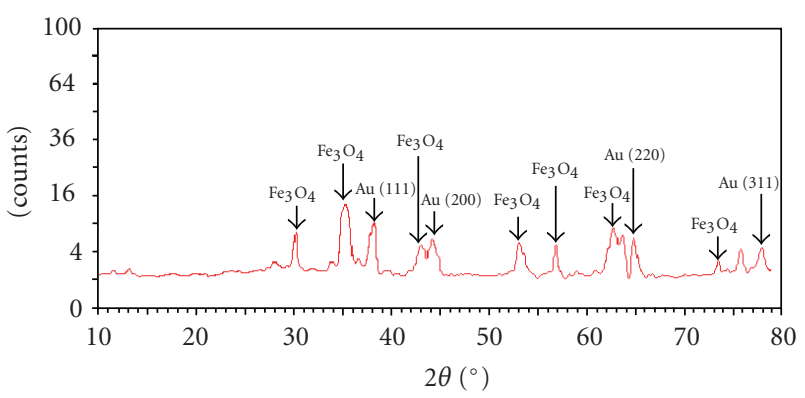

Figure 5: X-ray diffraction pattern of $\mathrm{Au}-\mathrm{Fe}_{3} \mathrm{O}_{4}$ composite nanoparticles.

\section{Acknowledgment}

This wok has been supported by Medicinal Plants Research Center, Faculty of Pharmacy, Tehran University of Medical Sciences, Tehran, Iran. 


\section{References}

[1] L. Wang, F. Wang, and D. Chen, "Fabrication and characterization of silver/polystyrene nanospheres with more complete coverage of silver nano-shell," Materials Letters, vol. 62, no. 14, pp. 2157-2160, 2008.

[2] X. F. Zhang, X. L. Dong, H. Huang, et al., "Synthesis, structure and magnetic properties of $\mathrm{SiO}_{2}$-coated $\mathrm{Fe}$ nanocapsules," Materials Science and Engineering A, vol. 454-455, pp. 211215, 2007.

[3] M. Pita, J. M. Abad, C. Vaz-Dominguez, et al., "Synthesis of cobalt ferrite core/metallic shell nanoparticles for the development of a specific PNA/DNA biosensor," Journal of Colloid and Interface Science, vol. 321, no. 2, pp. 484-492, 2008.

[4] Y. Q. Wang, K. Nikitin, and D. W. McComb, "Fabrication of Au- $\mathrm{Cu}_{2} \mathrm{O}$ core-shell nanocube heterostructures," Chemical Physics Letters, vol. 456, no. 4-6, pp. 202-205, 2008.

[5] X. G. Liu, D. Y. Geng, J. M. Liang, and Z. D. Zhang, "Magnetic stability of $\mathrm{Al}_{2} \mathrm{O}_{3}$-coated FCC-Co nanocapsules," Journal of Alloys and Compounds, vol. 465, no. 1-2, pp. 8-14, 2008.

[6] T. T. Pham, C. Cao, and S. J. Sim, "Application of citratestabilized gold-coated ferric oxide composite nanoparticles for biological separations," Journal of Magnetism and Magnetic Materials, vol. 320, no. 15, pp. 2049-2055, 2008.

[7] P. Tartaj, M. del Puerto Morales, S. Veintemillas-Verdaguer, T. González-Carreño, and C. J. Serna, "The preparation of magnetic nanoparticles for applications in biomedicine," Journal of Physics D, vol. 36, no. 13, pp. R182-R197, 2003.

[8] J. Jeong, T. H. Ha, and B. H. Chung, "Enhanced reusability of hexa-arginine-tagged esterase immobilized on gold-coated magnetic nanoparticles," Analytica Chimica Acta, vol. 569, no. 1-2, pp. 203-209, 2006.

[9] T. Kinoshita, S. Seino, Y. Mizukoshi, et al., "Magnetic separation of amino acids by gold/iron-oxide composite nanoparticles synthesized by gamma-ray irradiation," Journal of Magnetism and Magnetic Materials, vol. 293, no. 1, pp. 106$110,2005$.

[10] Z. Wang, H. Guo, Y. Yu, and N. He, "Synthesis and characterization of a novel magnetic carrier with its composition of $\mathrm{Fe}_{3} \mathrm{O}_{4}$ /carbon using hydrothermal reaction," Journal of Magnetism and Magnetic Materials, vol. 302, no. 2, pp. 397404, 2006.

[11] J. Lin, W. Zhou, A. Kumbhar, et al., "Gold-coated iron (Fe@Au) nanoparticles: synthesis, characterization, and magnetic field-induced self-assembly," Journal of Solid State Chemistry, vol. 159, no. 1, pp. 26-31, 2001.

[12] T. Kinoshita, S. Seino, K. Okitsu, T. Nakayama, T. Nakagawa, and T. A. Yamamoto, "Magnetic evaluation of nanostructure of gold-iron composite particles synthesized by a reverse micelle method," Journal of Alloys and Compounds, vol. 359, no. 1-2, pp. 46-50, 2003.

[13] S.-J. Cho, B. R. Jarrett, A. Y. Louie, and S. M. Kauzlarich, "Gold-coated iron nanoparticles: a novel magnetic resonance agent for T1 and T2 weighted imaging," Nanotechnology, vol. 17, no. 3, pp. 640-644, 2006.

[14] H. Yu, M. Chen, P. M. Rice, S. X. Wang, R. L. White, and S. Sun, "Dumbbell-like bifunctional $\mathrm{Au}-\mathrm{Fe}_{3} \mathrm{O}_{4}$ nanoparticles," Nano Letters, vol. 5, no. 2, pp. 379-382, 2005.

[15] K. Kawaguchi, J. Jaworski, Y. Ishikawa, T. Sasaki, and N. Koshizaki, "Preparation of gold/iron-oxide composite nanoparticles by a unique laser process in water," Journal of Magnetism and Magnetic Materials, vol. 310, no. 2, pp. 23692371, 2007.
[16] N. Ramezani, Z. Ehsanfar, F. Shamsa, et al., "Screening of medicinal plant methanol extracts for the synthesis of gold nanoparticles by their reducing potential," Zeitschrift fur Naturforschung B, vol. 63, no. 7, pp. 903-908, 2008.

[17] I. Martínez-Mera, M. E. Espinosa-Pesqueira, R. PérezHernández, and J. Arenas-Alatorre, "Synthesis of magnetite $\left(\mathrm{Fe}_{3} \mathrm{O}_{4}\right)$ nanoparticles without surfactants at room temperature," Materials Letters, vol. 61, no. 23-24, pp. 4447-4451, 2007.

[18] Q. H. Lu, K. L. Yao, D. Xi, Z. L. Liu, X. P. Luo, and Q. Ning, "Synthesis and characterization of composite nanoparticles comprised of gold shell and magnetic core/cores," Journal of Magnetism and Magnetic Materials, vol. 301, no. 1, pp. 44-49, 2006.

[19] J. Lim, R. D. Tilton, A. Eggeman, and S. A. Majetich, "Design and synthesis of plasmonic magnetic nanoparticles," Journal of Magnetism and Magnetic Materials, vol. 311, no. 1, pp. 78-83, 2007. 

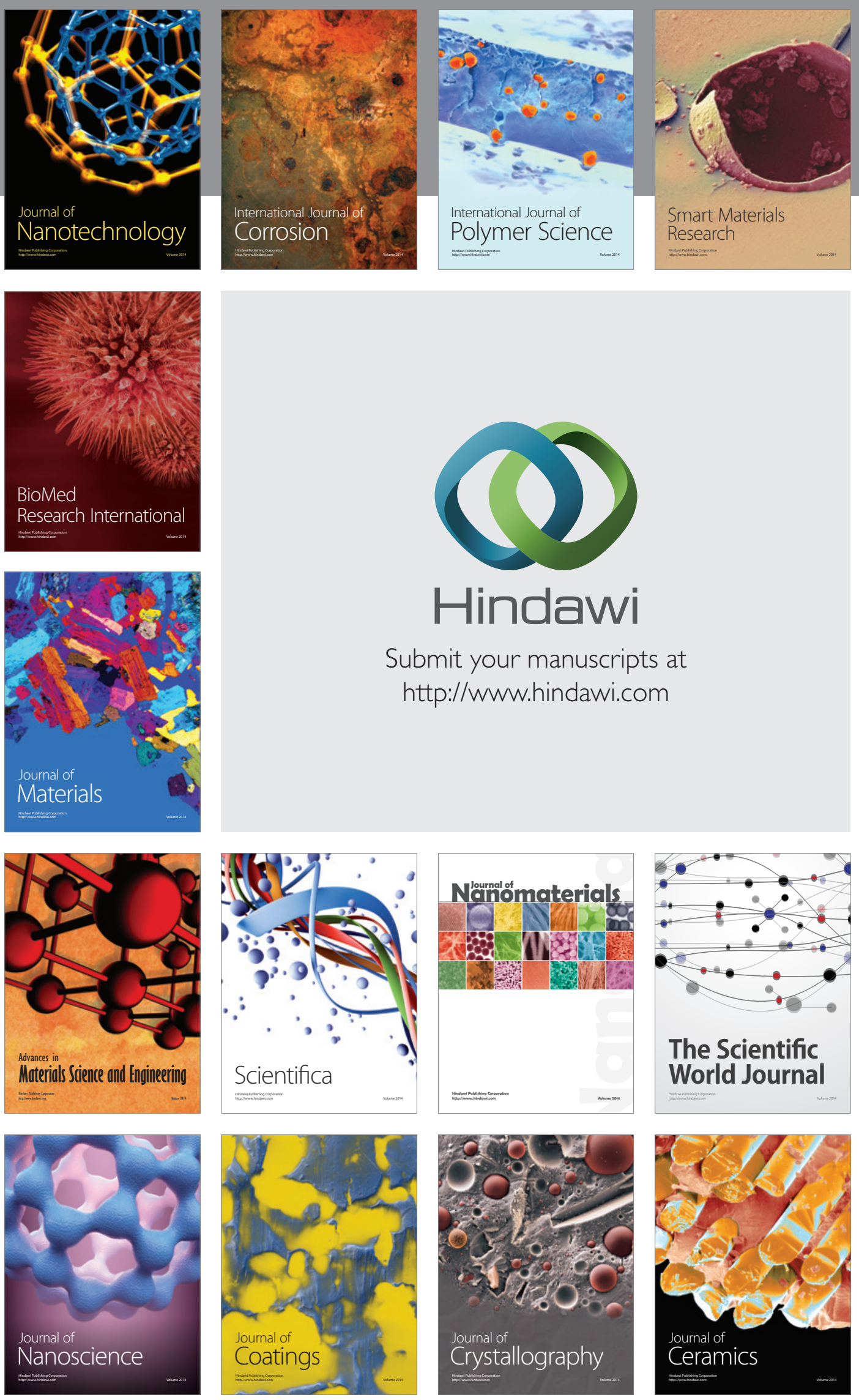

The Scientific World Journal

Submit your manuscripts at

http://www.hindawi.com

\section{World Journal}

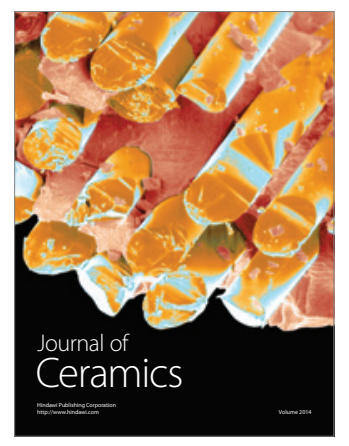

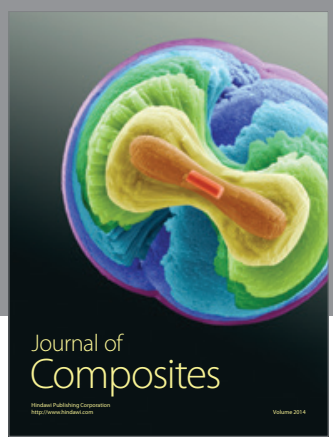
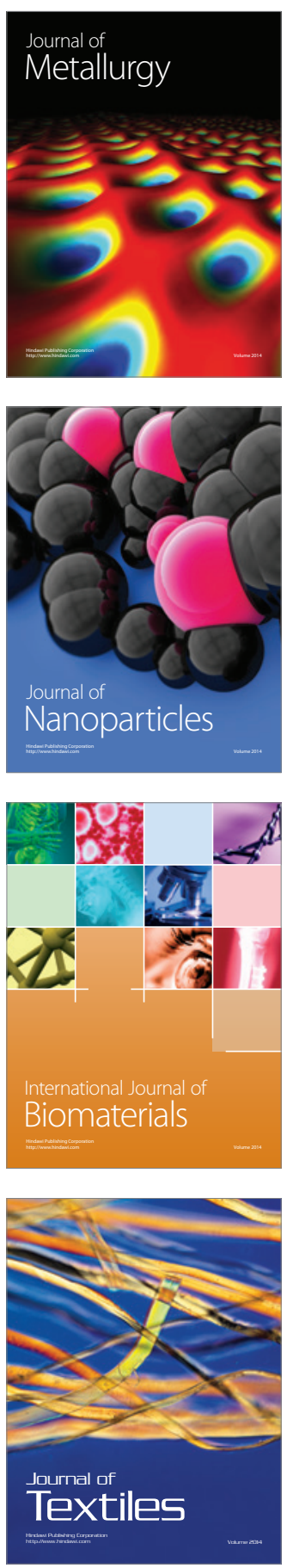